Western University Scholarship@Western

1980

\title{
Intertemporal Choice and International Trade
}

Joel Fried

Follow this and additional works at: https://ir.lib.uwo.ca/economicsresrpt

Part of the Economics Commons

Citation of this paper:

Fried, Joel. "Intertemporal Choice and International Trade." Department of Economics Research Reports, 8006. London, ON:

Department of Economics, University of Western Ontario (1980). 
ISBN: $\quad 0-7714-0163-9$

\section{RESEARCH REPORT 8006}

INTERTEMPORAL CHOICE AND INTERNATIONAL

TRADE

by

Joel Fried*

February 1980

* University of Western Ontario. I would like to thank Peter Howitt, Jim Markusen and Jim Melvin for valuable help in preparing this paper. Any errors that remain are mine. 
INTERTEMPORAL GHOICE AND INTERNATIONAL TRADE

\section{Introduction}

The purpose of this paper is to examine the effects of changes In relative prices on economic welfare when titles to income streams as well as flow commodities can be traded internationally. I show under what conditions the Introduction of trade in titles to income streams-capital flows--do and do not upset a number of the standard welfare results of the pure theory of trade when intertemporal choice is modeled along the IInes Implicit in International financial theory. In particular It 18 argued that if human and non-human capital are not treated as perfect substitutes in agents preferences then the imposition of tariffs (or a worsenting in the terms of trade) may make everyone in a small open economy better off. The reason for this result is that capital markets are implicitly assumed to be imperfect so that agents cannot treat their human capital as "Iiquid". If this market distortion were to be removed, then the traditional welfare implications of the Imposition of tariffs would continue to hold. However, the point of the exercise is not to argue that financial markets are perfect--they clearly are not--but rather it is an attempt to clarify some of the assumptions and issues that continue to divide pure theorists and financial theorists in modeling and understanding the international economy.

The next section models the individual intertemporal choice problem when tangible assets enter directly into the instantaneous utility function 
and Section III examines the economy-wide Implications of having agents with these preferences populating a small open economy. Section IV supposes that total wealth rather than tangible assets are included. In preferences and the implications of this assumption are then examined. Section $V$ argues that the assumptions of the previous section imply that the family of long-run price consumption curves indexed by: the. rate: of interest can be interpreted as commintty indifference curves despite the fact that agents do not have Identical preferences and Section VI makes some concluding comments. 
II. Individual Choice with Utility Yielding Assets

The agents in the small open economy I am considering act as if they maximize an infinite horizon, intertemporally additive preference functional where the "instantaneous" utility function has flow consumption and the value of asset stocks as arguments. For the $j^{\text {th }}$ agent at time $t_{0}$, this functional can be described as:

$$
\phi^{j}=\int_{t}^{\infty} \Omega^{j}\left(c_{t}^{j}, a_{t}^{j}\right) e^{-\delta^{j} t} d t
$$

where $c_{t}^{j}$ is the amount of the commodity consumed by $j$ at time $t$ and $a_{t}^{j}$ is the value of tangible assets held by $j$ at time $t$ measured in units of the flow commodity.

The income of the agent consists of interest income on $a_{t}^{j}$ plus autonomous receipts, ${ }^{1}{ }^{j}$, expected to remain constant forever:

$$
y_{t}^{j}=r a_{t}^{j}+h^{j}
$$

With this income the agent can either consume or add to his asset holdings according to the constraint

$$
\dot{a}_{t}^{j}=y_{t}^{j}-c_{t}^{j}=r a_{t}^{j}+h^{j}-c_{t}^{j} \text {. }
$$

To solve the agent's maximization problem, (1), subject to the constraints, (2), (3) and

$$
a_{t}^{j} \geq 0, \quad c_{t}^{j} \geq 0
$$

form the Hamiltonian function

$$
H^{j}(t)=e^{-\delta^{j}} t\left[\Omega^{j}\left(c_{t}^{j}, a_{t}^{j}\right)+\lambda^{j}\left(y_{t}^{j}-c_{t}^{j}\right)\right]
$$

Using the Maximum Principle:

$$
\Omega_{c}^{\mathbf{j}}=\lambda^{\mathbf{j}}
$$

and, since $\partial\left(\lambda e^{-\delta}{ }^{j}\right) / \partial t=-\partial H^{j}(t) / \partial a_{t}^{j}$,

$$
\lambda^{\mathbf{j}} / \lambda^{\mathbf{j}}=-\left[\Omega_{a}^{\mathbf{j}} / \lambda^{\mathbf{j}}+r-\delta^{\mathbf{j}}\right]
$$


Defining

$$
\sigma_{t}^{j}=-\frac{\Omega_{c c}^{j}}{\Omega_{c}^{j}} c_{t}^{j}, \quad \beta_{t}^{j}=\frac{\Omega_{c a}^{j}}{\Omega_{c}^{j}} a_{t}^{j}
$$

and using (5) and (3), (6) can be rewritten as

$$
\dot{c}_{t}^{j}=\left(\frac{c_{t}^{j}}{\sigma_{t}^{j}}\right)\left[\frac{\Omega_{a}^{j}}{\Omega_{c}^{j}}+r-\delta^{j}+\beta_{t}^{j} \frac{\left(y_{t}^{j}-c_{t}^{j}\right)}{h^{j}}\right]
$$

Equations (3) and (7) provide two differential equations in $c^{j}$ and $a^{j}$. Given $h^{j}$ and $r$, the possible equilibria are depicted in Figure 1. As Kurz FIGURE 1

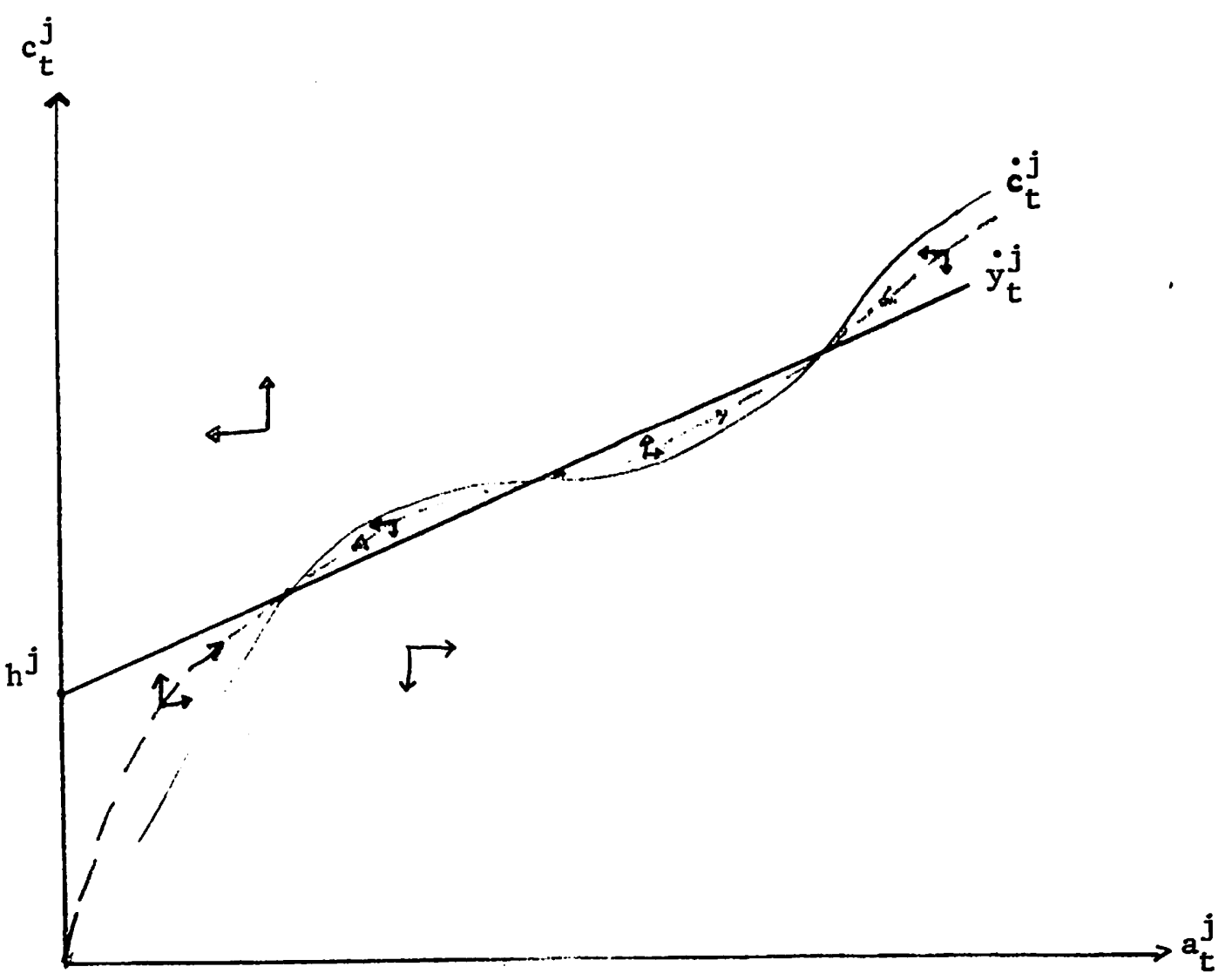

(1968) has shown, there need not be a unique stable equilibrium and, in particular, stability will depend on the third derivatives of $\Omega^{j}$. Even supposing that $\Omega^{j}()$ is separable and takes the form 


$$
\Omega^{j}\left(c_{t}^{j}, a_{t}^{j}\right)=U^{j}\left(c_{t}^{j}\right)+v^{j}\left(a_{t}^{j}\right)
$$

has some problems of interpretation. In this case the differential equations become:

$$
\begin{aligned}
& \theta_{1}^{j}\left(a_{t}^{j}, c_{t}^{j}\right)=\dot{a}_{t}^{j}=r a_{t}^{j}+h^{j}-c_{t}^{j} \\
& \theta_{2}^{j}\left(a_{t}^{j}, c_{t}^{j}\right)=\dot{c}_{t}^{j}=\left(\frac{c_{t}^{j}}{\sigma_{t}^{j}}\right) \frac{v^{j}()}{U^{j}()}+r-\delta^{j} J
\end{aligned}
$$

Assuming the existence of an equilibrium, stability requires that

$$
M^{j}\left(a^{j}, c^{j}\right) \equiv \partial c^{j} /\left.\partial a^{j}\right|_{\theta_{1}^{j}=0}-\partial c^{j} /\left.\partial a^{j}\right|_{\theta_{2}^{j}=0}>0
$$

which is satisfied if

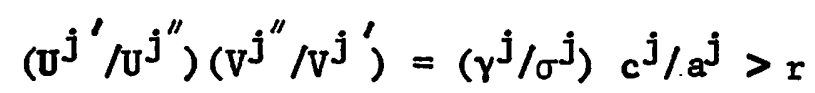

around equilibrium, where

$$
\gamma_{t}^{j}=-v^{j^{\prime \prime}} a_{t}^{j} / v^{j^{\prime}}>0
$$

(12) implies that stability depends on the relative elasticities of the marginal utilities of consumption $(\sigma)$ and wealth $(\gamma)$, about which we have little, if any, empirical information." However, the "stuff" of the pure theory of international trade is comparative static analysis and it will never do to have multiple stationary states for any given agent in the economy or to have none at all. Consequently, define the set $\bar{B}$ consisting . of all those arrays of $\left(r, h^{1}, h^{2}, \ldots, h^{N}\right) \equiv(r,[h])$ such that all agents, $j=1, \ldots, N$, in the economy possess a unique long-run personal equilibrium, $\left(\bar{c}^{-j}, \bar{a}^{j}\right)$;

$$
\begin{aligned}
& c^{-j}=c^{-j}\left(r, h^{j}\right) \\
& a^{-j}=a^{-j}\left(r, h^{j}\right)
\end{aligned}
$$

for all $(r,[h]) \in \bar{B}, \quad j=1, \ldots, N$.

For the rest of this paper, the analysis is restricted to $(r,[h])$ combinations 
in the (perhaps null) set $\bar{B}_{\bullet}^{3}$ For simplicity, the additive form of $\Omega^{j}$ given in (8) will be used in the rest of the paper.

To determine the effects of $r$ and $h^{j}$ on $c^{-j}$ and $a^{-j}$, set (9) and (10) equal to zero, substitute $\bar{c}^{-j}=h^{j}+r a^{-j}$ into (10) and differentiate:

$$
d^{-j}=\frac{\left[\left(\delta^{j}-r\right) U^{j^{\prime \prime}}()-U^{j^{\prime}}()\right] d r+\left[\left(\delta^{j}-r\right) U^{j^{\prime \prime}}()\right] d h^{j}}{\left[v^{j \prime}()+\left(r-\delta^{j}\right) U^{j^{\prime \prime}}()\right]}
$$

The coefficients in front of $\mathrm{dr}$ and $\mathrm{dh}^{j}$ in the numerator of (15) are both negative and, for stability, the denominator must be negative as well. Thus $\mathrm{d} \bar{a}^{-j} / \mathrm{dr}$ and $\mathrm{d} \mathrm{a}^{-j} / d h^{j}$ are positive, and from (9), $d \mathrm{c}^{-j} / d r$ and $d \mathrm{c}^{-j} / \mathrm{dh}^{\mathbf{j}}$ are also positive.

Equations (13) and (14) give the long-run demands for consumption and assets for any agent $j$. The short-run demand for consumption is

$$
\hat{c}_{t}^{j}=\hat{c}^{j}\left(r, h^{j}, a_{t}^{j}\right)
$$

where $\partial c_{t}^{j} / \partial a_{t}^{j}$ is positive. $\ddot{a}_{t}^{j}$ is then determined by substituting $\hat{c}_{t}^{j}$ from (16) for $c_{t}^{j}$ in equation (3).

To modify the above framework to permit both exports and imports it is necessary to redefine $c_{t}$ as a Hicksian composite commodity and deal with the issue of price indices. First, define

$$
c_{t}^{*}=T z_{1 t}+z_{2 t}
$$

where

$z_{1}$ is the exportable good

$z_{2}$ is the importable good

$T$ is the price of $z_{1}$ measured in units of $z_{2}$

and $\quad c^{*}$ is the composite flow commodity measured in units of $z_{2}$. 
Next, let $U^{j}\left(c_{t}^{j}\right)$ in (8) be replaced by $a^{j}\left(z_{1 t}^{j}, z_{2 t}^{j}\right)$ and define the indirect utility function:

$$
W^{j}\left(c_{t}^{* j}, T\right)=\max u^{j}\left(z_{1 t}^{j}, z_{2 t}^{j}\right) \text {, s.t. } T z_{1 t}^{j}+z_{2 t}^{j}=c_{t}^{* j} \text {. }
$$

If $u^{j}\left(z_{1 t}^{j}, z_{2 t}^{j}\right)$ is homothetic it can then be shown that $w^{j}\left(c_{t}^{*} ; T\right)$ can be rewritten as

$$
W^{j}\left(c_{t}^{* j} ; T\right)=W^{j}\left(c_{t}^{* j} / p^{j}(T)\right)
$$

where $\mathrm{p}^{j}(T)$ can be thought of as a personal price index for agent $j$ that converts units of $c^{*}$ into "real" (utility valued) consumption units. Interpreting $c_{t}^{j}$ as $c_{t}^{* j} / p^{j}(T)$ the analysis above could be duplicated with $w^{j}\left(c_{t}^{* j} / p^{j}(T)\right)$ replacing $u^{j}\left(c_{t}^{j}\right)$ in $(8)$.

Figure 2 may help to clarify the above discussion. Suppose the agent is consuming at point $A$ when faced with relative prices $T_{0} \cdot A s$ long as $T$ is constant, $c^{*}$ can serve as an index of the amount of utility generated by consumption. However, if $T$ falls to $T_{1}$, a given level of $c^{*}$ now Implies a greater level of utility, say $u_{1}\left(z_{1}, z_{2}\right)$ associated with point $B$. In this analysis this increase in utility is recorded by having the price index decline, increasing "real" consumption for a given level of consumption measured in units of $z_{2}$. Further, the change in the price index, $p\left(T_{1}\right) / p\left(T_{0}\right)$, that for a given $c{ }^{*}$ moved the agent from $u_{0}\left(z_{1}, z_{2}\right)$ to $u_{1}\left(z_{1}, z_{2}\right)$ can be measured by $0 c^{*} / 0 c^{*}$. Because $u\left(z_{1}, z_{2}\right)$ is homothetic this is the same as $\overline{O C} / \overline{O B}=\overline{O A} / \overline{O D}=\overline{O c} \overline{O C}^{*} / \overline{O C}^{\prime \prime}$. Thus the quantity index $c_{t}^{j}$, can take the multiplicative form $c_{t}^{* j} / p^{j}(T)$.

I would also argue that in $(8), v^{j}\left(a_{t}^{j}\right) \equiv v^{j}\left(a_{t}^{* j} / p^{j}(T)\right)$ where $a_{t}^{* j}$ is the value of assets held by $j$ at time $t$ measured in units of $z_{2}$ and $p^{j}(T)$ is the same price deflator as used to measure the real value of the composite consumption good. This assumption, while common in the monetary theory literature, 4 is by no means self evident. An argument for using it relates to the interpretation of assets in preferences as arising from their potential purchasing power if, 


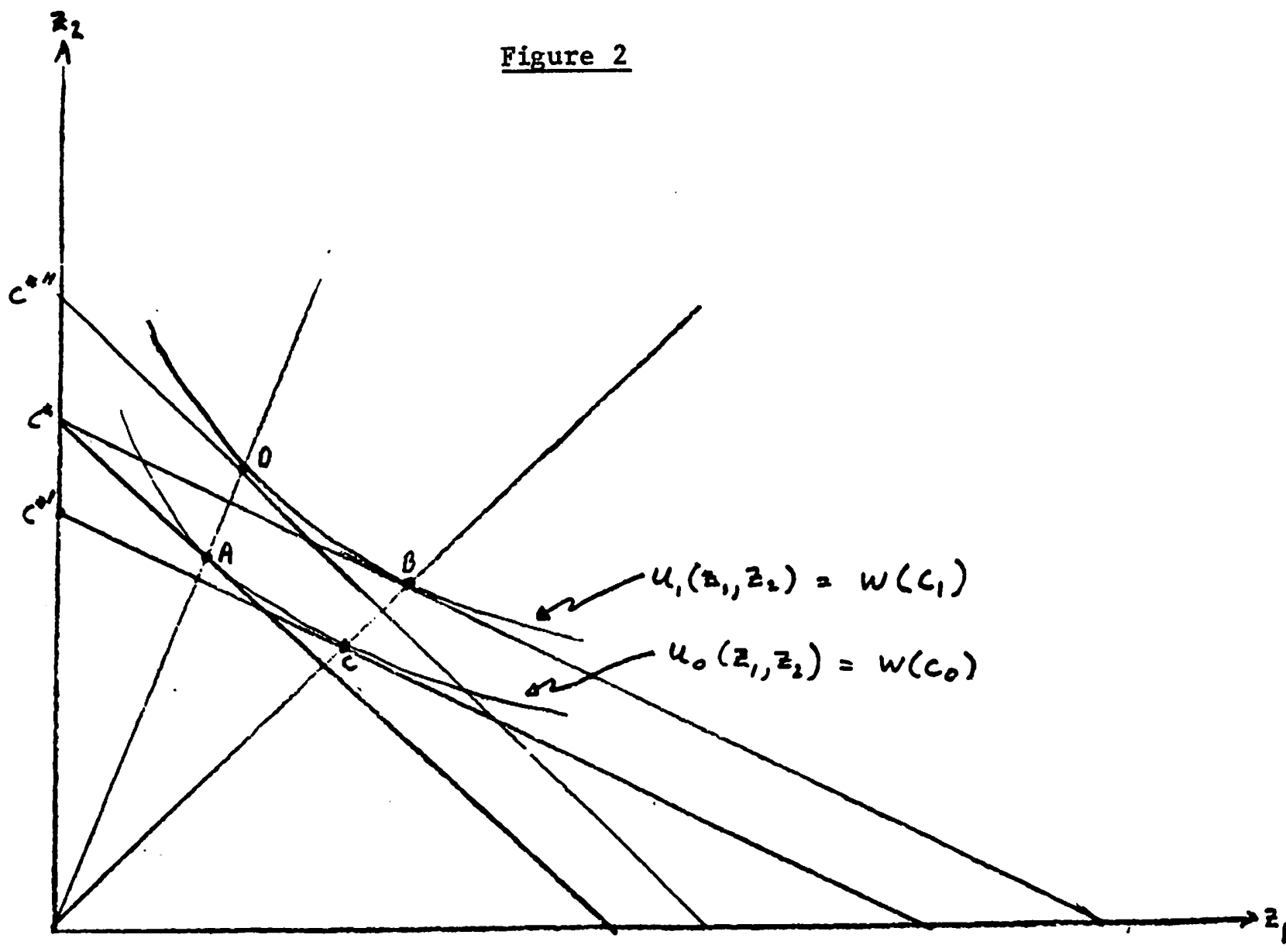

for some reason, other income streams fell. Thus the appropriate measure of real asset holding is the amount that is available to maintain a given real consumption plan (i.e., $c^{-* j} / p^{j}(T)$ ) in the face of fluctuating income from other sources. 5 . If this assumption is accepted then, upon substitution of $c_{t}^{* j} / p^{j}(T)$ and $a_{t}^{* j} / p^{j}(T)$ for $c_{t}^{j}$ and $a_{t}^{j}$ in (9) and (10), it follows immediately that the long-run demands for commodity flows and assets (measured in units of $z_{2}$ ) are

$$
\begin{aligned}
& c^{-* j}=p^{j}(T) c^{-j}\left(r, h^{j}\right) \\
& a^{-* j}=p^{j}(T) a^{-j}\left(r, h^{j}\right)
\end{aligned}
$$


for $(r,[h]) \in \bar{B}, p^{j \prime}(T)>0$ and $h^{j} \equiv h^{* j} / p^{j}(T)$, where $h^{* j}$ is autonomous receipts measured in unit's of $z_{2}$. Note that these long-run demand functions imply that a change in relative prices that does not alter $r$ or $h^{j}$ will not change the stationary state level of welfare, $W^{j}\left(c^{-j}\left(r, h^{j}\right)\right)$ $+V^{j}\left(a^{-j}\left(r, h^{j}\right)\right)$. This is only to say that the stationary state levels of consumption and real asset holding are independent of initial asset holdings when the proper price weighting scheme is used. It does not, of course, mean that if $r$ and $h^{j}$ are unchanged a change in $T$ will not alter short-run consumption and real asset holding: given $a_{t}^{* j}$, a change in $T$ will change $a_{t}^{* j} / p^{j}(T)$ and therefore, from $(16), c_{t}^{j}$.

In considering the change in welfare of an agent, $j$, it will be useful to distinguish between the impact effect, the Iong-run effect and the total effect on the level of welfare. The impact effect will be characterized by the change in the value of the instantaneous utility function at the time of the parameter change, to:

$$
\begin{aligned}
d \Omega^{j} /\left.d x\right|_{t=t_{0}} & =\left(d W^{j} / d\left(c^{* j} / p^{j}(T)\right)\left(d \hat{c}^{j}\left(r, h^{j}, a_{t_{0}}^{j}\right) / d x\right)\right. \\
& +\left(d v^{j} / d\left(a_{t_{0}}^{* j} / p^{j}(T)\right)\left(d a_{t_{0}}^{j} / d x\right)\right.
\end{aligned}
$$

The long-run effect will be characterized by the change in the value of the instantaneous utility function at $t=\infty$, i.e., after the agent has fully adjusted his asset holdings to their stationary state value given by (19):

$$
\begin{aligned}
\mathrm{d} \Omega^{j} /\left.\mathrm{dx}\right|_{t=\infty} & =\left(d W^{j} / d\left(\bar{c}^{-j} j / p(T)\right)\left(d c^{-j}\left(r, h^{j}\right) / d x\right.\right. \\
& +\left(d V^{j} / d a^{-j}\right)\left(d a^{-j}\left(r, h^{j}\right) / d x\right)
\end{aligned}
$$

The total effect of the parameter change on the level of welfare will be given by 


$$
\begin{aligned}
d \Psi^{j} / d x & =\int_{t_{0}}^{\infty}\left[w^{j}\left(\hat{c}^{j}\left(r, h^{j}, a_{t}^{j}\right)\right)+v^{j}\left(a^{-j}\left(r_{o}, h_{o}^{j}\right)+d a^{-j}\left(r_{o}, h_{o}^{j}\right) / d x\right.\right. \\
& \left.+y_{t}^{j}-\hat{c}^{j}\left(r, h^{j}, a_{t}^{j}\right)\right] e^{-\delta^{j} t} d t-\int_{t}^{\infty}\left[w^{j}\left(c^{-j}\left(r_{o}, h_{o}^{j}\right)\right)\right. \\
& +v^{j}\left(a^{-j}\left(r_{o}, h_{o}^{j}\right)\right] e^{-\delta^{j} t} d t
\end{aligned}
$$

where $r_{0}, h_{0}^{j}$ are the values of $r$ and $h^{j}$ prior to the parameter change. While the total effect on welfare is most important in making comparisons, unless both impact and long-run effects change welfare in the same direction the total effect generally cannot be determined without recourse to specific functional forms of $\mathrm{W}^{j}()$ and $\mathrm{V}^{j}()$.

\section{The ModeI}

The previous section described the individual choice problem for the agents populating the economy under analysis. In this section the economy itself is modeled.

The economy is assumed to be small and open so that both the terms of trade and the rate of interest are taken as given exogenously. Agents produce and consume the two flow commodities, exportables, $z_{1}$, and importables, $\mathrm{z}_{2}$. Production takes place under conditions of perfect competition using the two factors of production, labour, $N$, and capital, $K$, both of which are assumed fixed in supply. Technology is given and the domestic supplies of exportables and importables can be described by

$$
\begin{array}{ll}
s_{1}=s_{1}(T) & \partial s_{1} / \partial T>0 \\
s_{2}=s_{2}(T) & \partial s_{2} / \partial T<0
\end{array}
$$


respectively, where $T$ is the relative price of exportables in terms of the numeraire commodity, importables. The value of domestic output (in terms of $z_{2}$ ) is defined as

$$
Q^{*}=T s_{1}(T)+s_{2}(T)=w_{n} N+w_{k} K
$$

where $w_{n}$ is the wage rate for a unit of labour and $w_{k}$ is the rental rate on a unit of capital, both measured in units of $z_{2}$.

In this section it is assumed that agents can trade titles to domestic and foreign units of capital. Supposing unit elastic expectations regarding relative prices, the price of a title to a unit of domestic capital is

$$
P_{k} \equiv w_{k} / r
$$

and a title to a unit of foreign capital is

$$
P_{k f} \equiv w_{k f} / r
$$

where $w_{k f}$ is the rental price of a unit of capital located abroad. The aggregate holding of titles by domestic residents at time $t$ is

$$
A_{t}^{*}=P_{k} K+E_{f t}^{*}
$$

where $E_{f t}^{*}$ is the aggregate net holdings of foreign titles by domestic residents measured in units of $\mathrm{z}_{2}$ and $\mathrm{E}_{\mathrm{ft}}^{*} \gtrless 0$. To simplify, the convention will be adopted that gross holdings of foreign capital is zero if $A_{t}^{*}-P_{k} K \leq 0$, and equals net holdings if $A_{t}^{*}-P_{k} K>0$. A second convention adopted is that the home country will be designated a debtor (creditor) nation if $\mathrm{E}_{\mathrm{ft}}^{*}<0$ $\left(E_{f t}^{*}>0\right)$. Interest income from net holdings to foreign titles is $r E_{f t}^{*}$. The government of the home country has the power to levy taxes on any of the traded goods, the proceeds of which are immediately transferred to domestic residents. The convention that will be used here is that these proceeds are transferred equally among the $N$ agents in the economy with each agent receiving $1 / N$ of the proceeds. In an accounting sense these "net" transfers are to 
be interpreted as indirect taxes so that the measure of aggregate income in units of $z_{2}$ for the home country is

$$
\mathrm{Y}_{t}^{*}=T s_{1}(T)+s_{2}(T)+r E_{f t}^{*}+G_{t}^{*}
$$

where $G^{*}$ are net government transfers (or indirect tax proceeds).

Now consider the "autonomous receipts" for agents in the economy. For the economy as a whole, agents choose their level of holdings of capital so that $r E_{f t}^{*}+r P_{k} K=r E_{f t}^{*}+w_{k} K$ cannot be considered as autonomous to them. Consequently aggregate autonomous receipts measured in units of $z_{2}$ is:

$$
\begin{aligned}
H_{t}^{*} & =Y_{t}^{*}-\left(r E_{f t}^{*}+w_{k} K\right)=T s_{1}(T)+s_{2}(T)+G_{t}^{*}-w_{k} K \\
& =w_{n} N+G_{t}^{*}
\end{aligned}
$$

Supposing all agents in the economy work the same amount at the same wage and that each worker obtains $G_{t}^{*} / N \equiv g_{t}^{*}$ from the government then each agént will have autonomous receipts of

$$
h_{t}^{*}=w_{n}+g_{t}^{*}
$$

I now want to consider the effects of three parameter changes:

(1) an increase in the rate of interest, (2) an increase in the relative price of exports, and (3) an increase in tariffs. In considering these effects on the level of welfare for a representative agent it should be stressed that, because of the assumption $(r,[h]) \in \bar{B}$, all agents will be affected in qualitatively the same way insofar as their consumption and asset holdings are concerned both initially and in the long run. However if the impact and long-run effects of a parameter change on the welfare of the representative agent (given by (20) and (2i) above) are of different 
signs then it will generally be the case that the total welfare effect (22), will be qualitatively different for some "non-representative" agents. The representative agent is assumed to have autonomous receipts given by (23), holds assets $a_{t}^{*}=\left(E_{f t}^{*}+P_{k} K\right) / N$ and has a personal price index $p(T)$. For convenience it is supposed that $\mathrm{E}_{\mathrm{ft}}^{*}=0$ at the time of the parameter change. For an increase in interest rates the analysis of the previous section is sufficient since there are no feedback effects on other variables exogenous to the individual agents. 7 Thus, in the long run, an increase in $r$ causes both $\bar{a}^{*} / p(T)=\bar{a}$ and $\bar{c}^{*} / p(T)=\bar{c}$ to increase for the representative agent in the economy and given $(r,[h]) \in \bar{B}$, for every other agent as well. Therefore the long-run comparative static experiment of an increase in $r$ implies an unambiguous increase in welfare. On the other hand, the short-run impact effect implies just the opposite, for in that case every agent holding assets will suffer a capital loss with no change in real income. Consequently, observed consumption and asset holdings will be no greater than at the initial equilibrium and all agents will suffer a decrease in their instantaneous utility given by (20) above. Given these conflicting effects no statement can be made about the overall effect of an interest rate change on welfare of even the representative agent: It will depend on both tastes and on the ratio of autonomous receipts to asset holdings. The point to be stressed, however, is that looking only at the initial effect or only at the comparative static result will generally be a misleading indicator of the welfare effect of a change in interest rates.

In the previous section $I$ showed that a change in $T$ that did not affect either $r$ or $h^{j}$ would not affect long-run levels of welfare as measured by (21). Clearly however; a change in relative output prices will affect 
the real wage and hence $h^{j}$ for all workers. Suppose, in this next experiment, that there is an increase in $T$ that leaves the world rate of interest unchanged $^{8}$ and suppose further that the exportable good $z_{1}$, whose price has increased, is labour intensive. Then from the Stolper-Samuelson Theorem $w_{n}$ will increase relative to the price of both $z_{1}$ and $z_{2}$. Thus $h^{* j}$ and $h^{j}=h^{* j} / p^{j}(T)$ will increase for all $j$. Consequently, from (18), (19) and (21), long-run welfare would increase for all agents. The increase in $T$ also means that the domestic rental rate on capital falls relative to the price of both $z_{1}$ and $z_{2}$ and so all owners of domestic capital must suffer a capital loss on their real asset holdings, $a_{t}^{j}=a_{t}^{* j} / p^{j}(T)$. This capital loss will dominate the increase in the flow supply of output so that total resources available immediately after the change in $T$ will not permit the representative agent to maintain the instantaneous utility available prior to the change. Thus the impact effect on welfare of the increase in $T$, will likely ${ }^{9}$ be negative. The total welfare gain given by (22) from the increase in $T$ is therefore ambiguous.

If the home country's exportable is capital intensive then the reverse argument holds: The long-run comparative static result of an improvement in the terms of trade decreases both real consumption and real asset holding while in the short run both increase. The point that is to be stressed is that the welfare effect of a change in the terms of trade is ambiguous both in the short and long runs and depends on the labour intensity of the good with the increased relative price rather than upon which country is exporting it. In other words, in the absence of information about factor intensities, a worsening of the 
terms of trade of a nation is almost as likely to improve the welfare of a11 agents in an economy as is an improvement in the terms of trade. The reason for this is because ownership of capital generates a flow of direct utility as weIl as income to purchase flow commodities and, in order to get one, the agent must get the other. The change in the terms of trade alters both real income, and the direct utility. Consequently, in order to get the desired flow of utility services from capital in the long run, the real income generated by that ownership plus labour income will likely be altered so that a higher or lower level of sustained consumption can be maintained.

Next, consider the imposition of a tariff on the imported good. If it is assumed all agents in the home country are identical, such a tariff could improve the welfare of everyone in the country for reasons similar to a decrease in $T$ despite the fact that the country cannot influence, the real terms of trade. Suppose the tariff is levied on the labour intensive importable so that $T$ falls. Then not only is there the increase in autonomous receipts because of the increased wage but also because government indirect taxes and transfers have increased. Consequently, in the long run all agents are made better off because of the tariff. Further, if the short-run costs dominated the long-run gains from imposing a tariff on the labour intensive good, the argument could be reversed by supposing the import was capital intensive. It therefore appears that even in the absence of monopoly power the imposition of a tariff may be welfare improving for a nation under fairly standard conditions.

\section{Implicit Titles to Income Streams}

Whenever it turns out that a tariff is capable of improving everyone's welfare in a country, the immediate response is (or should be) to suggest that some distortion in markets is causing this perverse result. Such a market distortion is involved in this case as well. I believe this distortion is 
that the present value of income arising from different sources is treated differently in agents' preferences. Why it is treated this way implicitly is because trades in markets for titles to income other than from capital are not permitted to exist. The argument that it is liquidity needs that generate the utility services to tangible assets suggests this interpretation. If agents are permitted to borrow on their future labour income, then human capital would generate liquidity services as well. Furthermore, in the monetary economics literature at least, the capitalization of income streams other than from tangible assets have long played a role, especially those associated with future tax and transfers (cf. Patinkin (1965) and Barro (1974)). In this section the basic description of choice behavior is altered to include implicit titles to income streams and the international trade implications are then examined.

To examine the effects of treating income as if an explicit market for titles to it existed it is assumed that the asset measure over which preferences are defined is

$$
\tilde{a}_{t}^{* j}=a_{t}^{* j}+h^{* j} / r=a_{t}^{* j}+\frac{1}{r}\left[w_{n}+g^{* j}\right]
$$

For the economy as a whole this is the same as discounted income, $\mathrm{Y}_{t}^{*} / \mathrm{r}$, so that for the representative agent

$$
\tilde{a}_{t}^{*}=\mathrm{y}_{t}^{*} / \mathrm{rN} \equiv \mathrm{y}_{t}^{*} / \mathrm{r}
$$

Preferences and constraints for this representative agent are

$$
\phi=\int_{0}^{\infty}\left[w\left(c_{t}\right)+V\left(\tilde{a}_{t}\right)\right] e^{-\delta t} d t
$$

subject to

$$
\dot{\tilde{a}}_{t}=r \tilde{a}_{t}-c_{t}
$$

and

$$
\tilde{a}_{t}, z_{1 t}, z_{2 t}>0
$$

where $c_{t}=c_{t}^{*} / p(T)$ and $\tilde{a}_{t}=\tilde{a}_{t}^{*} / p(T)$ are measured in real terms. 
Again using the Maximum Principle the system can be described by the two differential equations

$$
\begin{aligned}
& \Psi_{1}\left(\tilde{a}_{t}, c_{t}\right)=\dot{\tilde{a}}_{t}=r \tilde{a}_{t}-c_{t} \\
& \Psi_{2}\left(\tilde{a}_{t}, c_{t}\right)=\dot{c}_{t}=\left(c_{t} / \sigma_{t}\right)\left(V^{\prime} / w^{\prime}+r-\delta\right)
\end{aligned}
$$

The stability condition is the same as $(14)$ where $\tilde{a}_{t}$ replaces a $a_{t}$ but note that in the stationary state $r \tilde{a}_{t}=c_{t}$ so that stability is assured if

$$
\tilde{\gamma}>\sigma
$$

about equilibrium, where

$$
\tilde{\gamma}_{t}=-V^{\prime \prime} \tilde{a}_{t} / V^{\prime} \text { and } \sigma=-w^{\prime \prime} c_{t} / w^{\prime} \text {. }
$$

Again, assuming a unique stable long-run equilibrium for each agent, (24) and (25) are characterized in Figure 3. An increase in the rate of interest will shift $\dot{c}=0$ to $\dot{c}^{\prime}=0$ and $\dot{\tilde{a}}=0$ to $\dot{\tilde{a}}^{\prime}=0$ increasing the

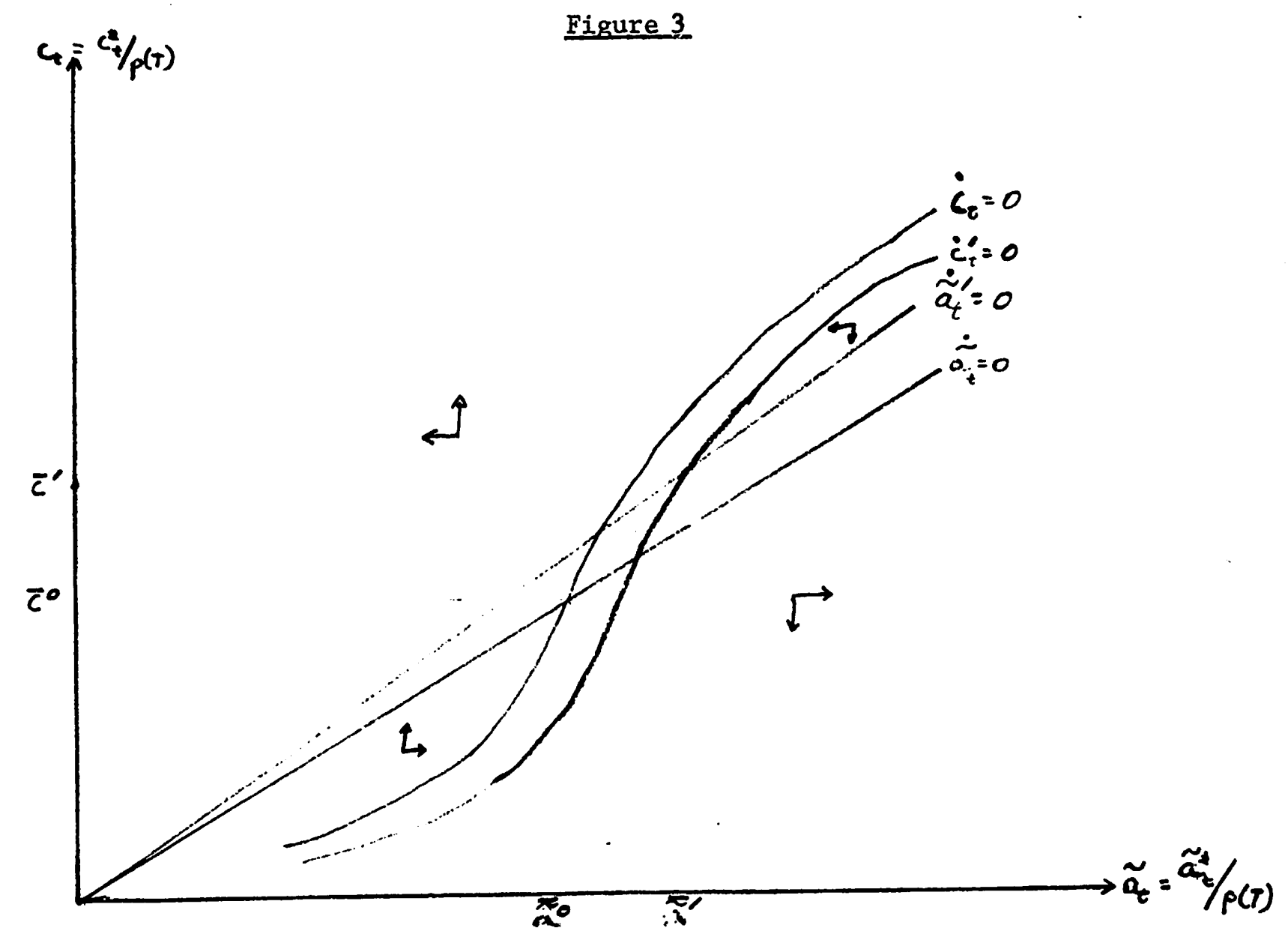


long-run stationary state to $\left(\overline{\tilde{a}}^{\prime}, \bar{c}^{\prime}\right)$ from $\left(\overline{\tilde{a}}^{0}, \bar{c}^{0}\right)$. Because the same price index is used for both $c$ and $\tilde{a}$, an increase in the terms of trade, $T$, will increase $c^{*}$ and $\hat{a}^{*}$ measured in units of $z_{2}$ but will leave the real (utility) value of $c$ and $\tilde{a}$ unchanged in the long run. In the short run of course $c^{*} / p(T)$ and a $/ P(T)$ will change with an increase in $T$. However, if $E_{f t}$ is small it is known that the impact effect of an increased $\mathrm{T}$ will increase real income and therefore $a^{* / p}(T)$ so that short-run welfare is increased. Therefore $\frac{c_{t}^{*}}{p(T)} \geq \frac{\bar{s}^{0^{*}}}{p\left(T^{0}\right)}$ and $\frac{\tilde{a}_{t}^{*}}{p(T)} \geq \frac{\tilde{a}^{* 0}}{p\left(T^{0}\right)}$ so that overall welfare has been increased. A tariff, on the other hand reduces the relative price of the exportable good and, even taking into account government transfers, will reduce real income in the short run but leave it unchanged in the long run. Consequently tariffs are welfare reducing to the representative citizen of the country imposing them although these costs will not show up in the long-run comparative static experiment if the country is small.

If the country can influence relative prices through its tariff policy then the measure of world welfare loss will be recorded by a fall in the rate of interest. The mechanism by which it does so is through an increase in asset demand as agents attempt to increase their real incomes to the pre-tariff levels. In Figure 3 this increase forces the rate of interest down shifting the $\dot{c}=0$ curve leftward and the $\dot{\tilde{a}}=0$ curve rightward until equilibrium world real consumption is reduced to equal the lower world real income caused by the now inefficient use of factors of production.

V. Iong-Run Price Consumption Curves and Community Indifference Curves From the above discussion and equations it is clear that the long-run demands for consumption goods and assets for any agent can be described by 


$$
\begin{array}{ll}
\bar{c} * j=p^{j}(T) \bar{c}^{j}(r) & \bar{c}^{\prime}<0 \\
\overline{\widetilde{a}} *=p^{j}(T) a^{j}(r) & \overline{\widetilde{a}}>0
\end{array}
$$

Furthermore, (26) and (27) imply that in the stationary. state, utility Is Invariant with respect to relative output prices for all agents. Consequently, given $x=\underline{x}$, the long-run price consumption curve for $z_{1}^{j}$ and $z_{2}^{j}$, all $j$, is income compensated so that it describes the agent's instantaneous indifference curve for $W^{j}\left(c^{-j}(\underline{I})\right)$. Given that this is true for all agents in the economy it follows that the aggregate price consumption curve for given $r$ also has constant utility levels along it. Finally, since $(r,[h]) \in \bar{B}$, an Increase in $r$ causes every agent's longrun utility to increase and there is a family of aggregate price consumption curves indexed by the rate of interest that for all intents and purposes can be designated as "communtty indifference curves" 10 and haye the same important properties of convexity and transitivity of individual Indifference curves.

In arriving at this derivation of comminity indifference curves the assumptions about preferences have been (1) preferences for consumption goods are homothetic; (2) preferences are separable over time and between wealth and the composite flow commodity; (3) the price index for real asset holdings is the same as for composite consumption; (4) wealth 18 capitalized Income; and (5) over the relevant range, a unique stable long-run equilibrium exists for each agent. It was not supposed that all agents have 1dentical tastes. Does the construction in this paper then provide a counterexample to Samielson's "proof" of the 1mpossibility of constructing community Indifference curves if agents do not have identical homothetic 
preferences (Samuelson, 1956, pp. 4-5)? The answer is no because the conceptual experiments are completely different. For Samuelson, the experiment supposes a fixed endowment $\left(\underline{z}_{1}^{j}, \underline{z}_{2}^{j}\right)$ for all $j$. For my analysis, agents choose their long-run "endowments" through the process of saving or dissaving income earning assets. Assumptions (1)-(5) ensure that each agent's long-run "real" endowment is not affected by the terms of trade so that relative income levels among agents are fixed for a given interest rate. Removing these income effects is sufficient to remove the requirement that agents must have identical tastes.

One assumption that has played a critical role in the entire analysis is that $(r,[h]) \in \bar{B}$. This assumption says only that confronted with a given array of relative prices (including the interest rate) each agent, $j$, will consistently choose the same Iong-run consumption and asset holding plan for al1 $j$. Such an assumption is not necessary if the choice set is restricted to flow commodities alone (cf. Clower, 1968) as was common in much of the pure trade theory literature, but if claims on income streams can be traded, such an assumption becomes necessary if many of the trade theory propositions are not to be mitigated. Suppose, for instance, that trade in titles to income streams can only be traded within the economy. Without an assumption such as $(r,[h]) \in \bar{B}$ it is quite possible for one agent to plan to save at all interest rates greater than zero (i.e., $\delta^{j}-\nabla^{j} / w^{j} \leq 0$ for some agent $j$ ). Since ownership of any land or claims on labour income necessarily implies that the rate of interest must be positive, there can be no long-run comparative static exercises because the Iong-run stationary state will not exist. Furthermore, even if restrictions on preferences were such that the stationary state did exist, the robustness of many of the propositions of trade theory are reduced. This is because distribution effects play a potentially greater 
role if stocks as well as flows can be traded and if multiple (personal) equilibria are not assumed away. Not only are there the normal distribution effects for a given endowment from, say, a change in relative prices, but also such a shock may set in motion a process of saving and dissaving that may easily magnify the distribution effects over time. The assumption $(r,[h]) \in \bar{B}$ is a means, therefore, of minimizing these effects when analyzing the pure theory of international trade.

\section{Concluding Remarks}

In this paper I have shown that tariffs can, in principle, improve welfare for all agents in a small open economy measured either as the discounted stream of utility when the tariff is instituted or by consumption and asset holdings in the new stationary state (if, as assumed, the stationary state exists and is unique). For such a welfare improving tariff to exist in this model it is necessary that all income streams not be treated as "usable" wealth. If there are perfect markets for all income streams it was shown that a tariff on importables would not change welfare in a comparison of long-run stationary states but there would be a welfare loss associated with the transition to the new stationary state. Thus, the result of welfare improving tariffs relies on market imperfections or distortions in an intertemporal context the same as in the "one period" context of traditional pure theory models.

One implication of the assumptions used in the perfect market model 18 that the long-run price consumption curves in an economy are income compensated so that the welfare of each and every agent is constant along them. It is therefore 
possible to reinterpret the long-run price consumption curve at any $r$ as a long-run community indifference curve. Further, an increase in $r$ will imply, in the long run, an increase in consumption of all flow commodities at any set of relative prices for these flows and a new long-run price consumption curve : along which all agents are better off than before.

One implication of this for the long-run gains from international trade relative to autarky is that, if the assumptions used for the perfect market model hold then, in the long run, agents of an economy will be worse off with international trade than in autarky if the world rate of interest is less than the country's rate of interest was in autarky. In effect, agents obtain the gains from trade during the transition to the new stationary state by selling claims on income leaving themselves in the long run with lower real assets, income and, therefore, consumption. A second implication that holds if assets cannot be traded internationally but a perfect market for income streams prevails within the economy is that the domestic interest rate serves as an index of the long-run welfare gains from trade. 
FOOTNOTES

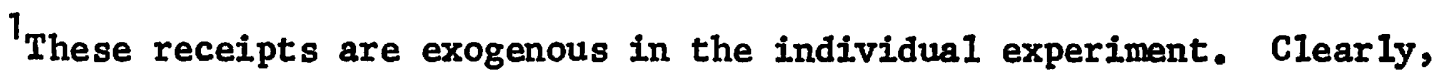
for the system as a whole they are endogenous and will be treated as such in subsequent sections.

${ }^{2}$ Clower and Johnson (1968) have developed a model of consumption behavior similar to the model developed here and subjected it to empirical test. The evidence seems to suggest that most, but not all, individuals are operating near a stable stationary equilibrium and that the shocks that have occurred do not move them to a different stationary state.

${ }^{3}$ If all agents had $v^{j}\left(a^{j}\right) \equiv 0$ and constant discount rates--the standard intertemporal choice problem--a non-trivial stationary state equilibria would not exist: (1) If $\delta>r$ then $\bar{a}=0$; (2) If $\delta<r$, then $a_{t}$ will grow without limit; and (3) $r=\delta, \bar{a}$ is undefined. If (1) prevailed then the welfare index is autonomous receipts; If (2) then agents in the home country would end up owning the world (or at least as much as could be purchased) and the small country assumption would no longer apply.

4 This assumption means the demand for money and bonds depends on the absolute price level and not relative prices. Cf. Patinkin (1965).

$5_{A}$ second argument is related to the equal ignorance principle: Without specific additional information about what $z_{1}$ and $z_{2}$ are and how payments are arranged, we haven't a clue as to whether the price index for assets should relate more to $z_{1}$ or $z_{2}$ purchases or sales than the price index for commodity flows. In the absence of specific information we might as well treat the indices for flows and for stocks as the same. 
$6^{6}$ It should be noted that the only place in the rest of the text where the assumption of identical preferences is used is in considering the imposition of a tariff when only tangible assets enter preferences.

${ }^{7}$ Such a change could occur, for instance, from an exogenous increase in the rate of time preference of non-residents $\left(\delta_{f}\right)$.

${ }^{8}$ Such an experiment could occur, for instance, if the home country was unilaterally given most favoured nation status by its trading partners.

${ }^{9}$ This qualification arises if asset holdings are very small: If some agent held no assets he would suffer no capital losses and thus would unambiguously gain.

10 These offer curves also have the property of being consistent with the concept of social welfare functions where the market mechanism and individual choice but not initial endowments provide the weighting scheme. 


\section{REFERENCES}

Barro, R. J., "Are Government Bonds Net Wealth?" Journal of Political Economy, Nov/Dec 1974, Pp. 1095-1118.

Clower, R. W., "Stock-Flow Analysis" in International Encyclopedia of the Social Sciences, Vol. 15, Macmillan Co. and the Free Press, 1968, pp. 273-277.

Clower, R. W., and M. B. Johnson, "Income, Wealth and the Theory of Consumption" in J. N. Wolfe, Value, Capital and Growth, Aldine, 1968.

Kurz, M., "Optimal Economic Growth and Wealth Effects," International Economic Review, Oct. 1968, pp. 348-57.

Patinkin, D。, Money, Interest and Prices, 2nd edition, Harper and Row, 1965. Samuelson, P. A., "Social Indifference Curves," Quarterly Journal of Economics, Feb. 1956, pp. 1-22.

Samuelson, P. A., and W. F. Stolper, "Protection and the Real Wage," Review of Economic Studies, Sept. 1941, pp. 304-317. 